\title{
Metabolic syndrome is associated with different clinical outcome after cardiac resynchronization therapy in patients with ischemic and non-ischemic cardiomyopathy
}

Barbara Szepietowska, Scott McNitt, Bronislava Polonsky, Saadia Sherazi, Yitschak Biton, Valentina Kutyifa, Mehmet K. Aktas, Arthur J. Moss, Wojciech Zareba University of Rochester Medical Center, Rochester, New York, United States

\begin{abstract}
Background: Although association of metabolic syndrome (MS) and ischemic heart disease is strongly established, it is not known whether presence of MS may differently influence clinical responses to cardiac resynchronization therapy (CRT). The aim of this study was to evaluate the associations between obesity and metabolic features and the clinical outcome after cardiac resynchronization with defibrillator therapy (CRT-D), compared to an implantable cardioverter defibrillator (ICD).
\end{abstract}

Methods: The risk of heart failure (HF) or death and death alone was evaluated in 829 non-obese patients, 156 obese patients without MS, and 277 obese patients with MS (all with left bundle branch block), who were enrolled in the Multicenter Automatic Defibrillator Implantation Trial with Cardiac Resynchronization Therapy (MADIT-CRT).

Results: Obese patients with MS (HR 0.50, 95\% CI 0.32-0.77, $p=0.002$ ), obese patients without MS (HR 0.57, 95\% CI 0.30-1.06, $p=0.077$ ), and non-obese patients (HR 0.48, 95\% $C I 0.37-0.62, p<0.001)$ had a similar risk reduction of $H F /$ death in response to CRT-D therapy when compared to ICD patients. However, among those with non-ischemic cardiomyopathy, obese patients with MS experienced a $90 \%$ reduction for $\mathrm{HF} /$ death $(\mathrm{HR} 0.11,95 \% \mathrm{CI}$ $0.04-0.32, p<0.001$ ), whereas obese patients without MS had no reduction (HR 0.98, 95\% CI 0.48-1.98, $p=0.951$; interaction $p<0.001)$. The reverse was observed in ischemic cardiomyopathy patients: obese patients with MS had no reduction in the risk of HF/death (HR 0.80, 95\% CI 0.48-1.34, $p=0.402$ ), while obese patients without MS showed a significant reduction in the risk of events (HR 0.15, 95\% CI 0.04-0.65, $p=0.011$; interaction $p=0.036$ ). Similar trends were observed for the endpoint of death.

Conclusions: Presence of MS differentiates the response to CRT in obese patients with ischemic and non-ischemic etiology for HF. (Cardiol J 2016; 23, 3: 344-351)

Key words: obesity, metabolic syndrome, cardiac resynchronization therapy, implantable cardioverter defibrillator, heart failure, clinical outcome

Address for correspondence: Barbara Szepietowska, MD, University of Rochester Medical Center, Cardiology Division, Heart Research Follow-up Program, 265 Crittenden Blvd., PO Box 653, Rochester, NY 14642, United States, tel: 585-275-5391, fax: 585-273-5283, e-mail: barbara.szepietowska@heart.rochester.edu 


\section{Introduction}

In the United States (US), two thirds of the adult population are overweight or obese [1], and the prevalence of obesity is rising worldwide [2]. Obesity is a risk factor for heart failure (HF) in the general population [3], but the relation of obesity to cardiovascular disease outcomes is not very well understood, and it is known as the "obesity paradox". The presence of obesity in patients with established cardiovascular disease is associated with favorable clinical prognosis [4]. In our previous analysis, weight loss but not presence of obesity increased the risk for $\mathrm{HF} /$ death after cardiac resynchronization therapy with defibrillator (CRT-D) [5].

It has been postulated that metabolic syndrome (MS) is a better reflection of complex association between metabolic disturbances and high cardiovascular risk [6-8]. Indeed, studies consistently showed that patients with MS have an increased risk for $\mathrm{HF}$ and myocardial infarction [9-14]. To our knowledge, clinical response to cardiac resynchronization therapy (CRT) in patients with MS has not been evaluated before.

The aim of the current study was to assess whether the presence of MS in addition to obesity would affect clinical prognosis after CRT and whether ischemic vs. non-ischemic etiology for $\mathrm{HF}$ in obese patients with and without MS would differentiate the response to CRT-D.

\section{Methods}

\section{Study population}

The results and the protocol of the Multicenter Automatic Defibrillator Implantation Trial with Cardiac Resynchronization Therapy (MADIT-CRT) trial have been previously reported [15]. Patients of either sex who were at least 21 years old, with ischemic cardiomyopathy (NYHA class I or II) or non-ischemic cardiomyopathy (NYHA class II only), sinus rhythm, an ejection fraction of $30 \%$ or less, and prolonged intraventricular conduction (QRS duration with $\geq 130 \mathrm{~ms}$ ) were randomly assigned in 3:2 ratio to receive CRT-D or implantable cardioverter defibrillator (ICD) only. The MADIT-CRT trial was carried out from December 2004 through September 2010. Post-trial follow-up was conducted for all surviving study participants. After September 10, 2010, ongoing patient follow-up was conducted in 48 US centers that agreed to participate in the long-term follow-up requested by the Food and Drug Administration for patients enrolled in the US and in 23 of 24 non-US centers involving a total of 854 patients, 407 in the US registry and 447 in non-US registry. Both phases of the post-trial follow-up were approved by the institutional review board of each participating center and all the patients provided their written informed consent. Patients had an ambulatory follow-up 1 month after the device implantation, and every 3 months thereafter until the termination of the trial, as well as every 6 months after the trial. All the patients had clinical evaluation at each follow-up appointment or at any meaningful clinical event.

\section{Definitions of subgroups}

In the current analysis, only patients with left bundle branch block (LBBB) were evaluated, in concordance with previously published clinical benefit present exclusively in this group of patients $[16,17]$. We designed an analysis to compare the risk of $\mathrm{HF}$ or death, whichever comes first, among obese patients with and without MS and non-obese patients. Patients with obesity were defined as body mass index (BMI) $\geq 30 \mathrm{~kg} / \mathrm{m}^{2}$ at baseline appointment. Patients with MS were defined based on the modified International Diabetes Federation criteria for MS [18]. BMI $\geq 30 \mathrm{~kg} / \mathrm{m}^{2}$ at baseline was used for definition of obesity and the presence of hypertension, or baseline systolic blood pressure $\geq 130 \mathrm{~mm} \mathrm{Hg}$, or diastolic blood pressure $\geq 85 \mathrm{~mm} \mathrm{Hg}$ was used as a definition for elevated blood pressure. The following modification of the original definition was applied to account for plasma lipids disturbances: fibrates, statins, and any other present lipid lowering therapy. Diabetes was reported by the enrolling centers at the time of device implantation, and in this study, it serves as a marker for hyperglycemia. Patients with obesity and additionally accompanied by features of MS were required to have at least 2 of the 4 criteria: fibrate, statin or any other lipid lowering therapy, diabetes, or hypertension [18]. Patients with ischemic heart disease were defined to have at least 1 of the following: a documented history of myocardial infarction ( $Q$-wave or enzyme-positive), a history of a coronary revascularization procedure ( $\geq 1$ previous coronary artery bypass graft surgeries or percutaneous coronary interventions), documented significant coronary artery disease at coronary angiography, or aggregate clinical findings, for example, history of angina pectoris or other coronary-related symptoms or signs.

\section{Endpoints}

The primary endpoint was HF or death, whichever came first. The secondary endpoint was death. 
The diagnosis of HF was given by physicians at the enrolling centers, when patients presented with signs and symptoms consistent with congestive HF that prompted intravenous decongestive treatment in an outpatient setting or augmented decongestive therapy with oral or parenteral drug administration at the hospital. Adjudication of the endpoints of $\mathrm{HF}$ or death was carried out by independent committees who were blinded to the treatment assignment, according to pre-specified criteria.

\section{Statistical analysis}

Baseline clinical characteristics were compared using nonparametric Wilcoxon for continuous variables and the $\chi^{2}$ test or Fisher's test for dichotomous variables, as appropriate. We performed Kaplan-Meier survival analyses of unadjusted cumulative event rates stratified by obesity and the presence of MS with the log-rank test statistics. We estimated hazard ratios (HR) for primary and secondary endpoints using the Cox proportional hazards regression method. The independent variables were chosen using the best subset selection method. We followed this statistical methodology because we wanted to develop a parsimonious model which excluded variables that were not significantly predictive of the endpoints and would have very little impact on the results. In this way, we attempted to maximize the statistical power, an important consideration in the subgroup analysis. Age and sex were forced in the model. Possible interactions with clinical covariates were systematically tested. Final covariates that were used and adjusted for the models are reported in specific tables. Analyses were carried out with SAS software (version 9.3, SAS institute, Cary, North Carolina).

\section{Results}

The study population consisted of 1,262 patients; 277 (22\%) obese patients with MS, 156 (12\%) obese patients without MS and $829(66 \%)$ non-obese patients in the extended follow-up trial. The median follow-up of the enrolled patients was 5.6 years (interquartile range: $1.8-3.2$ ). Clinical and demographic characteristics of the study population are presented in Table 1. In summary, obese patients with MS were older, more likely male, had an ischemic etiology of $\mathrm{HF}$, and lower glomerular filtration rate. Usage of angiotensin converting enzyme inhibitors, beta-blockers and diuretics was similar in both groups.
Obese patients with MS had lower left ventricular (LV) end-diastolic volume and LV endsystolic diameter, whereas LV septal and posterior wall thicknesses were higher compared to patients with obesity only. Patients with MS and obesity had higher LV mass compared to non-obese subjects at the baseline appointment (Table 1).

\section{The effect of CRT-D vs. ICD therapy on mortality and HF/death endpoints}

When analyzing all patients combined, CRT-D treatment significantly reduced the risk for $\mathrm{HF} /$ /death in obese with MS ( $<<0.001)$ and non-obese patients $(\mathrm{p}<0.001)$, while reduction in events in patients without MS was borderline significant $(\mathrm{p}=0.088)$ (Fig. 1A-C). Consistently, multivariate Cox model showed that CRT-D treatment in obese patients with MS, patients without MS, and nonobese patients was associated with similar HR of $0.50,0.57$, and 0.48 , respectively (Table 2 ).

The underlying etiology for HF influenced the effect of CRT-D on the risk or HF/death and death in obese patients with respect to the presence of MS. CRT-D treatment reduced the risk of $\mathrm{HF} /$ death in obese patients with MS and with non-ischemic cardiomyopathy by $90 \%$ ( $p<0.001)$. Similarly, for death, the same group had $76 \%$ reduction in mortality associated with CRT-D vs. ICD treatment.

The opposite was found in patients with ischemic cardiomyopathy: obese patients with MS did not show benefit from CRT-D, whereas obese patients without MS showed substantial 85\% reduction in HF/death events $(\mathrm{p}=0.011)$ and $81 \%$ reduction in the risk of death $(\mathrm{p}=0.077)$. The $\mathrm{p}$ value for interaction was 0.036 when considering $\mathrm{HF} /$ death events and 0.118 when analyzing death (Table 2, Fig. 2).

Non-obese patients showed a similar reduction in $\mathrm{HF} /$ death and death in the total study population, as well as in ischemic and non-ischemic cardiomyopathy subgroups (Table 2, Fig. 3).

\section{Discussion}

Our analysis indicates that the presence of the MS is associated with different clinical responses to CRT-D in patients with ischemic and non-ischemic cardiomyopathy. There was no evidence of differences in clinical benefit from CRT-D between ischemic and non-ischemic in non-obese patients. This is an unexpected finding, because non-ischemic cardiomyopathy patients were reported to present with better clinical re- 
Table 1. Baseline clinical characteristics of MADIT-CRT patients by presence of metabolic syndrome (MS).

\begin{tabular}{|c|c|c|c|c|c|}
\hline Clinical variables & $\begin{array}{l}\text { Obese patients } \\
\text { with MS }\end{array}$ & $\begin{array}{l}\text { Obese patients } \\
\text { without MS }\end{array}$ & $\begin{array}{l}\text { Non-obese } \\
\text { patients }\end{array}$ & $\begin{array}{l}\text { P: MS vs. } \\
\text { no MS }\end{array}$ & P: Overall \\
\hline Age [years] & $63.1 \pm 9.4$ & $57.4 \pm 11.6$ & $66 \pm 10.6$ & $<0.001$ & $<0.001$ \\
\hline Body mass index $\left[\mathrm{kg} / \mathrm{m}^{2}\right]$ & $34.3 \pm 4.3$ & $33.6 \pm 3.3$ & $25.6 \pm 2.9$ & 0.237 & $<0.001$ \\
\hline Female & $71(26 \%)$ & $54(35 \%)$ & $260(31 \%)$ & 0.048 & 0.087 \\
\hline White & $251(91 \%)$ & $140(90 \%)$ & $758(92 \%)$ & 0.832 & 0.669 \\
\hline CRT-D treatment & $156(56 \%)$ & $102(65 \%)$ & $492(59 \%)$ & 0.065 & 0.182 \\
\hline Ischemic NYHA I and II & $156(56 \%)$ & $28(18 \%)$ & $374(45 \%)$ & $<0.001$ & $<0.001$ \\
\hline Non-Ischemic NYHA II & $121(44 \%)$ & $128(82 \%)$ & $455(55 \%)$ & $<0.001$ & $<0.001$ \\
\hline Prior MI & $111(41 \%)$ & $23(15 \%)$ & $267(33 \%)$ & $<0.001$ & $<0.001$ \\
\hline Prior CABG & $80(29 \%)$ & $10(6 \%)$ & $189(23 \%)$ & $<0.001$ & $<0.001$ \\
\hline Prior HF hospitalization & $102(37 \%)$ & $70(45 \%)$ & $310(38 \%)$ & 0.101 & 0.196 \\
\hline Glomerular filtration rate $[\mathrm{mL} / \mathrm{min}]$ & $70 \pm 22$ & $74 \pm 19$ & $68 \pm 20$ & 0.014 & 0.004 \\
\hline Systolic blood pressure & $126 \pm 18$ & $119 \pm 15$ & $122 \pm 17$ & $<0.001$ & $<0.001$ \\
\hline Diastolic blood pressure & $73 \pm 11$ & $73 \pm 11$ & $71 \pm 10$ & 0.791 & 0.007 \\
\hline \multicolumn{6}{|l|}{ Metabolic parameters } \\
\hline Diabetes & $169(61 \%)$ & $1(1 \%)$ & $211(25 \%)$ & $<0.001$ & $<0.001$ \\
\hline Hypertension & $241(87 \%)$ & $60(38 \%)$ & $493(60 \%)$ & $<0.001$ & $<0.001$ \\
\hline Lipid lowering excluding & $61(22 \%)$ & $13(8 \%)$ & $98(12 \%)$ & $<0.001$ & $<0.001$ \\
\hline Statins & $234(84 \%)$ & $47(30 \%)$ & $516(62 \%)$ & $<0.001$ & $<0.001$ \\
\hline \multicolumn{6}{|l|}{ Baseline drug treatment } \\
\hline ACE-inhibitors & $212(77 \%)$ & $121(78 \%)$ & $634(76 \%)$ & 0.807 & 0.955 \\
\hline Beta-blocker & $262(95 \%)$ & $148(95 \%)$ & $775(93 \%)$ & 0.898 & 0.740 \\
\hline Diuretics & $214(77 \%)$ & $115(74 \%)$ & $530(64 \%)$ & 0.408 & $<0.001$ \\
\hline \multicolumn{6}{|c|}{ Baseline echocardiography parameters } \\
\hline LVEF & $28.5 \pm 3.4$ & $28.5 \pm 3.2$ & $28.8 \pm 3.5$ & 0.965 & 0.409 \\
\hline LVEDV indexed by BSA & $121 \pm 27$ & $126 \pm 29$ & $128 \pm 31$ & 0.063 & 0.003 \\
\hline LVESV indexed by BSA & $87 \pm 22$ & $91 \pm 24$ & $92 \pm 26$ & 0.089 & 0.023 \\
\hline LAV indexed by BSA & $46 \pm 9$ & $46 \pm 11$ & $48 \pm 10$ & 0.510 & 0.003 \\
\hline LV mass & $229 \pm 42$ & $227 \pm 47$ & $209 \pm 37$ & 0.477 & $<0.001$ \\
\hline LV septal wall thickness & $0.84 \pm 0.07$ & $0.81 \pm 0.07$ & $0.81 \pm 0.07$ & 0.001 & $<0.001$ \\
\hline LV posterior wall thickness & $0.83 \pm 0.06$ & $0.81 \pm 0.07$ & $0.80 \pm 0.07$ & 0.004 & $<0.001$ \\
\hline
\end{tabular}

Values are given as total number of patients and percentage or mean \pm standard deviation; ACE - angiotensin converting enzyme; BSA - body surface area; CABG — coronary artery bypass graft surgery; HF — heart failure; LV - left ventricle; LVEF — left ventricular ejection fraction; LVEDV - left ventricular end-diastolic volume; LVESV - left ventricular end-systolic volume; LAV - left atrial volume; NYHA - New York Heart Association class

sponse to CRT-D than ischemic cardiomyopathy ones [19-21]. Our current data indicate that these findings could be associated with the obesity and MS status.

Molecular mechanism of CRT is attributed to activation of the same pathway as insulin signaling $\mathrm{PKB} / \mathrm{AKt}$ pathway [22]. It is well known that falling heart will switch fuel metabolism from long chain fatty acids to glucose, but in people with MS also glucose is less available for the heart due to the fact that people with MS have profound insulin resistance and reduced glucose uptake, especially in the presence of ischemia [23]. This may explain why the presence of non-ischemic etiology for HF is associated with better clinical response after CRT-D in general population $[19,24]$ and in our study, in people with MS.

A recent paper by Chokshi et al. [25] suggested that implantation of $\mathrm{LV}$ assist device reversed myocardial lipotoxicity and improved myocardial insulin resistance. It is interesting to speculate that similarly to LV assist device, the CRT treatment also affects cardiac myocardium by direct effect on myocardial metabolism [22, 26, 27]. It may affect 


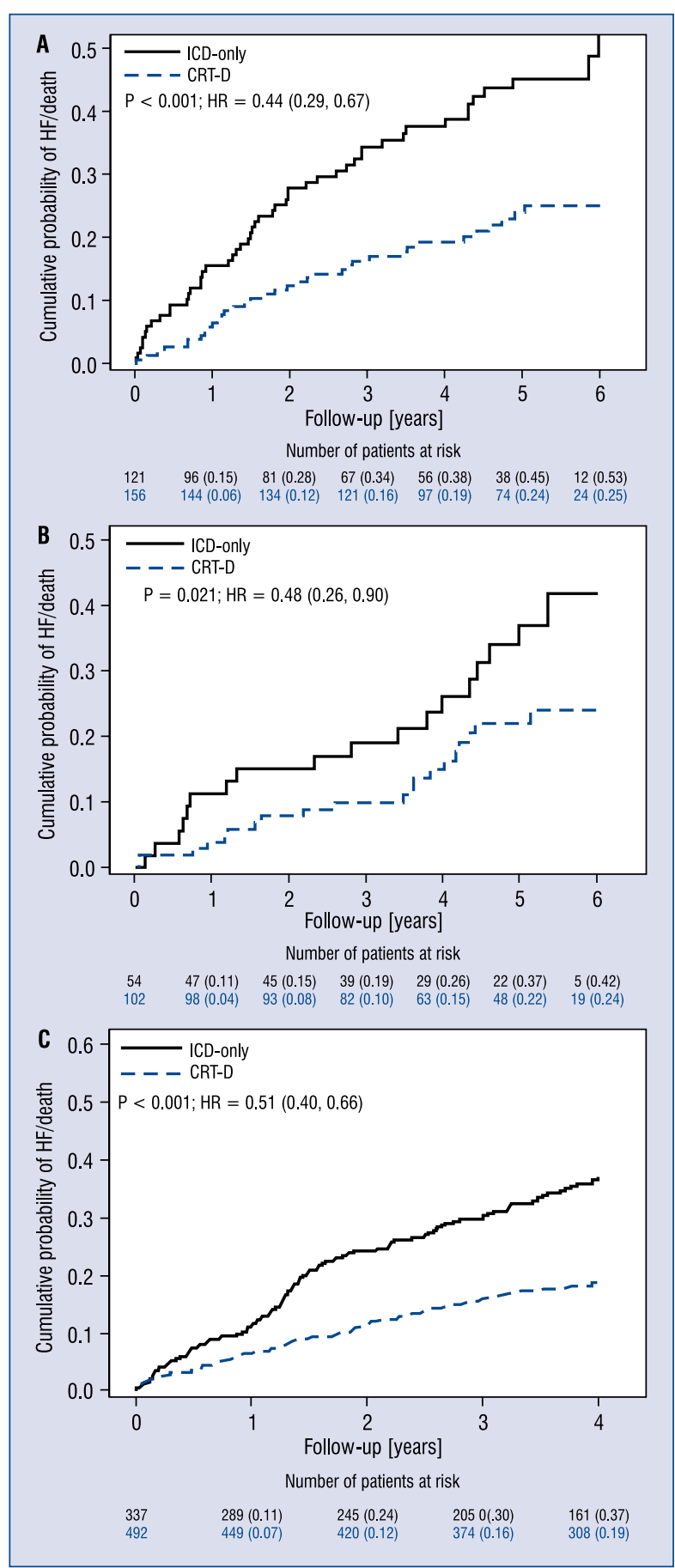

Figure 1. Cumulative probability of heart failure (HF)/ /death in obese patients with metabolic syndrome (A), obese patients without metabolic syndrome (B) and non-obese patients (C).

heart muscle metabolism towards utilization of long chain fatty acids or better utilization of glucose. In people with MS and ischemic cardiomyopathy, this effect of CRT could be limited and translate into higher risk of $\mathrm{HF} /$ death.
The molecular mechanism postulated for the pathogenesis of cardiac complications in obesity includes lipotoxicity [28], inflammation, oxidative stress [29], apoptosis [30] and sympathetic overactivation [31]. Obesity leads to the loss of cardiomyocytes, cardiac dysfunction and ultimately HF [32]. An unexpected finding of our analysis is that patients with obesity without metabolic components had better reduction in mortality and $\mathrm{HF} /$ death when having ischemic cardiomyopathy despite similar up front risk. This may suggest paradoxical cardioprotection of the myocardium from ischemic injury in obese patients without disturbances of myocardium metabolism/insulin sensitivity reflected as the presence of co-morbidities associated with clinical manifestation of MS.

\section{Limitations of the study}

Metabolic syndrome diagnosis was a modification of original diagnosis based on presence of the pharmacological therapy, aiming to treat clinical presentation for MS. This was a retrospective, nonrandomized post-hoc study, with a relatively small number of patients in the subgroup analysis. An adjusted multivariate analysis was performed, taking into account many confounders associated with analyzed endpoints and those that played a significant role in the outcome in our population.

\section{Conclusions}

Our findings indicate that non-obese ischemic and non-ischemic cardiomyopathy patients with mild HF derive similar benefit from CRT-D vs. ICD. However, the presence of MS differentiates response to CRT stratified by presence of ischemic or non-ischemic cardiomyopathy. Obese non-ischemic cardiomyopathy patients derive significant benefit from CRT-D if they present with MS, whereas obese patients without MS show no significant reduction in events. On the contrary, obese ischemic cardiomyopathy patients with MS show no benefit from CRT, while obese ischemic patients without MS show significant reduction in the risk of events. This study suggests that the risk for $\mathrm{HF} /$ death and response to CRT in people with obesity depends on the presence of MS, especially complicated by HF. Although it is only speculative, this study also suggests that intrinsic properties of myocardium fuel metabolism affected by MS may play a role in response to CRT. Future studies are needed to investigate the mechanism of CRT in 
Table 2. Risk of heart failure or death with CRT-D vs. ICD by ischemic and non-ischemic etiology and by metabolic syndrome (MS).

\begin{tabular}{|c|c|c|c|c|c|c|c|}
\hline \multirow[t]{2}{*}{$\begin{array}{l}\text { Patients } \\
\text { subgroup }\end{array}$} & \multicolumn{2}{|c|}{$\begin{array}{l}\text { Obese patients } \\
\text { with MS }\end{array}$} & \multicolumn{2}{|c|}{$\begin{array}{l}\text { Obese patients } \\
\text { without MS }\end{array}$} & \multicolumn{2}{|c|}{$\begin{array}{l}\text { Non-obese } \\
\text { patients }\end{array}$} & \multirow{2}{*}{$\begin{array}{c}\text { P: } \\
\text { Metabolic } \\
\text { obese X } \\
\text { treatment }\end{array}$} \\
\hline & $\begin{array}{l}\text { Patients; } \\
\text { events }\end{array}$ & $\begin{array}{c}\mathrm{HR}(95 \% \mathrm{Cl}) \\
\text { P }\end{array}$ & $\begin{array}{l}\text { Patients; } \\
\text { events }\end{array}$ & $\begin{array}{c}\mathrm{HR}(95 \% \mathrm{CI}) \\
\text { P }\end{array}$ & $\begin{array}{l}\text { Patients; } \\
\text { events }\end{array}$ & $\begin{array}{c}\mathrm{HR}(95 \% \mathrm{Cl}) \\
\text { P }\end{array}$ & \\
\hline \multicolumn{8}{|c|}{ Heart failure or death } \\
\hline All patients & $270 ; 84$ & $\begin{array}{c}0.50(0.32-0.77) \\
\mathbf{0 . 0 0 2}\end{array}$ & $154 ; 40$ & $\begin{array}{c}0.57(0.30-1.06) \\
0.077\end{array}$ & $816 ; 246$ & $\begin{array}{c}0.48(0.37-0.62) \\
<0.001\end{array}$ & 0.726 \\
\hline $\begin{array}{l}\text { Ischemic } \\
\text { disease }\end{array}$ & $152 ; 60$ & $\begin{array}{c}0.80(0.48-1.34) \\
0.402\end{array}$ & $28 ; 8$ & $\begin{array}{c}0.15(0.04-0.65) \\
\mathbf{0 . 0 1 1}\end{array}$ & $367 ; 140$ & $\begin{array}{c}0.43(0.30-0.60) \\
<0.001\end{array}$ & 0.036 \\
\hline $\begin{array}{l}\text { Non-ischemic } \\
\text { disease }\end{array}$ & $118 ; 24$ & $\begin{array}{c}0.11(0.04-0.32) \\
<0.001\end{array}$ & $126 ; 32$ & $\begin{array}{c}0.98(0.48-1.98) \\
0.951\end{array}$ & $449 ; 106$ & $\begin{array}{c}0.54(0.37-0.80) \\
\mathbf{0 . 0 0 2}\end{array}$ & $<0.001$ \\
\hline \multicolumn{8}{|l|}{ Death } \\
\hline All patients & $270 ; 33$ & $\begin{array}{c}0.70(0.35-1.40) \\
0.319\end{array}$ & $154 ; 18$ & $\begin{array}{c}0.47(0.18-1.20) \\
0.117\end{array}$ & $816 ; 126$ & $\begin{array}{c}0.65(0.46-0.93) \\
\mathbf{0 . 0 1 7}\end{array}$ & 0.506 \\
\hline $\begin{array}{l}\text { Ischemic } \\
\text { disease }\end{array}$ & $152 ; 25$ & $\begin{array}{c}0.95(0.43-2.10) \\
0.898\end{array}$ & $28 ; 5$ & $\begin{array}{c}0.19(0.03-1.20) \\
0.077\end{array}$ & $367 ; 84$ & $\begin{array}{c}0.68(0.44-1.04) \\
0.081\end{array}$ & 0.118 \\
\hline $\begin{array}{l}\text { Non-ischemic } \\
\text { disease }\end{array}$ & $118 ; 8$ & $\begin{array}{c}0.24(0.05-1.12) \\
0.082\end{array}$ & $126 ; 13$ & $\begin{array}{c}0.83(0.30-2.50) \\
0.736\end{array}$ & $449 ; 42$ & $\begin{array}{c}0.55(0.29-1.03) \\
0.058\end{array}$ & 0.214 \\
\hline
\end{tabular}

After adjustment for age, sex, glomerular filtration rate, diabetes, heart rate, ischemic cardiomyopathy, and left atrial volume at baseline indexed by body surface area and interval PR; HR - hazard ratio; Cl - confidence interval; CRT-D — cardiac resynchronization with defibrillator therapy; ICD — implantable cardioverter defibrillator

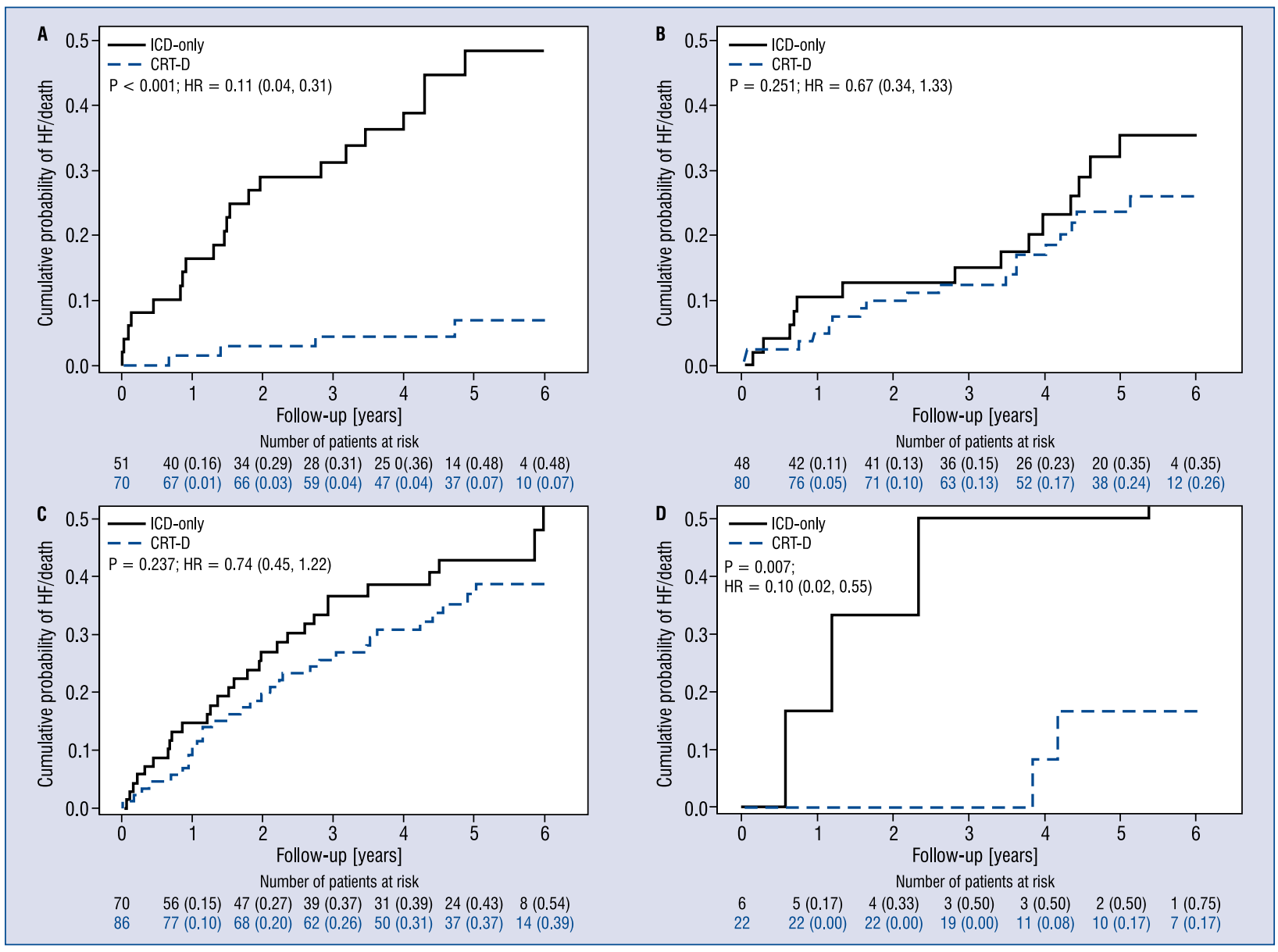

Figure 2. Cumulative probability of heart failure (HF)/death among patients with ischemic and non-ischemic cardiomyopathy by obesity status in obese patients with metabolic syndrome $(\mathbf{A}, \mathbf{B})$, and obese patients without metabolic syndrome (C, D). 


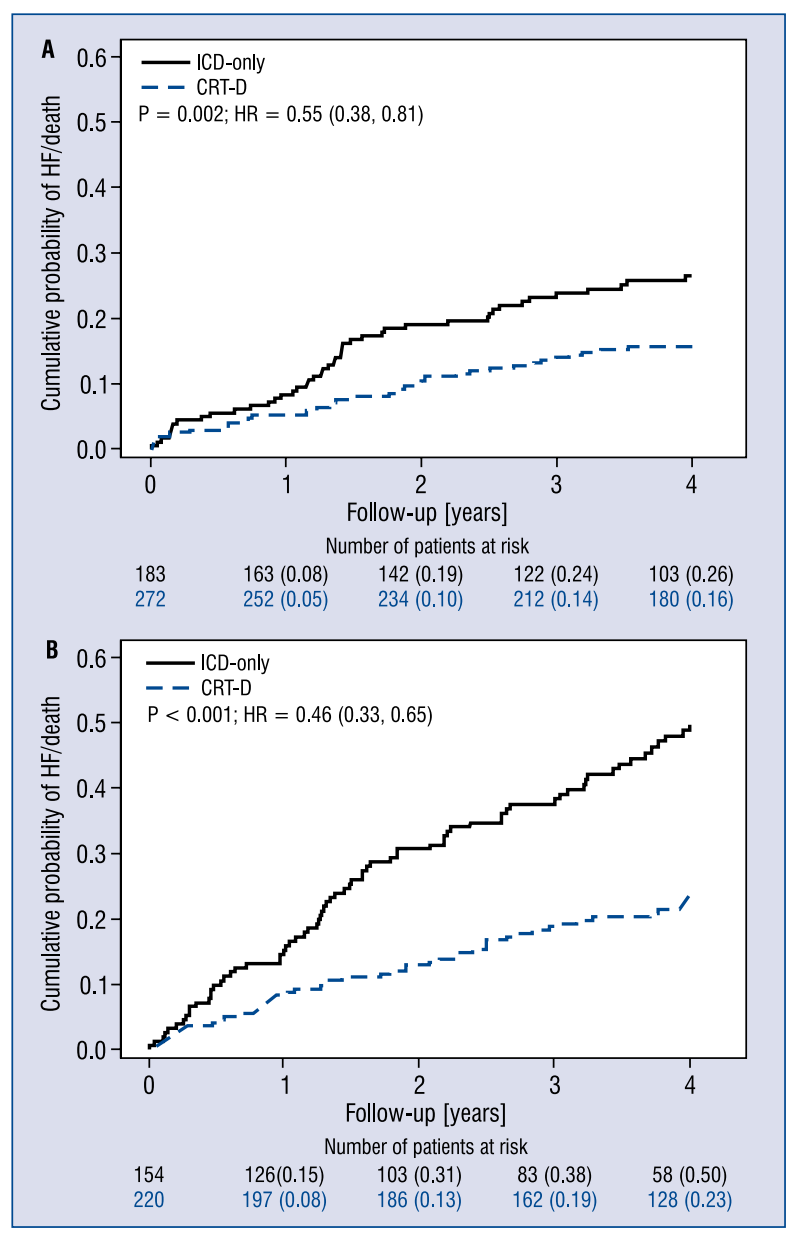

Figure 3. Cumulative probability of heart failure (HF)/death among non-obese patients with non-ischemic cardiomyopathy (A) and ischemic cardiomyopathy (B).

relation to myocardium fuel metabolism and cellular responses in a falling heart.

Clinical trial registration: NCT00180271, NCT01294449, NCT02060110.

Conflict of interest: The MADIT-CRT study was supported by a research grant from Boston Scientific to the University of Rochester, with funds distributed to the coordination and data center, enrolling centers, core laboratories, committees, and boards under subcontracts from the University of Rochester.

\section{References}

1. Flegal KM, Carroll MD, Ogden CL, Johnson CL. Prevalence and trends in obesity among US adults, 1999-2000. JAMA, 2002; 288: 1723-1727.

2. Global Burden of Metabolic Risk Factors for Chronic Diseases Collaboration (BMI Mediated Effects), Lu Y, Hajifathalian K,
Ezzati M, Woodward M, Rimm EB, Danaei G. Metabolic mediators of the effects of body-mass index, overweight, and obesity on coronary heart disease and stroke: A pooled analysis of 97 prospective cohorts with 1.8 million participants. Lancet, 2014; 383: 970-983. doi: 10.1016/S0140-6736(13)61836-X.

3. Kenchaiah S, Evans JC, Levy D et al. Obesity and the risk of heart failure. N Engl J Med, 2002; 347: 305-313.

4. Lavie CJ, Alpert MA, Arena R, Mehra MR, Milani RV, Ventura HO. Impact of obesity and the obesity paradox on prevalence and prognosis in heart failure. J Am Coll Cardiol Heart Fail, 2013; 1: 93-102. doi: 10.1016/j.jchf.2013.01.006.

5. Aktas MK, Zareba W, Huang DT et al. The effect of weight loss on clinical outcomes in patients implanted with a cardiac resynchronization therapy device-A MADIT-CRT substudy. J Card Fail, 2014; 20: 183-189. doi: 10.1016/j.cardfail.2013. 12.012 .

6. Reaven GM. Insulin resistance, cardiovascular disease, and the metabolic syndrome: How well do the emperor's clothes fit? Diabetes Care, 2004; 27: 1011-1012.

7. Miranda PJ, DeFronzo RA, Califf RM, Guyton JR. Metabolic syndrome: Definition, pathophysiology, and mechanisms. Am Heart J, 2005; 149: 33-45.

8. Grundy SM, Cleeman JI, Daniels SR et al. Diagnosis and management of the metabolic syndrome: An American Heart Association/National Heart, Lung, and Blood Institute Scientific Statement. Circulation, 2005; 112: 2735-2752.

9. Moreira GC, Cipullo JP, Ciorlia LA, Cesarino CB, Vilela-Martin JF. Prevalence of metabolic syndrome: Association with risk factors and cardiovascular complications in an urban population. PLoS One, 2014; 9: e105056. doi: 10.1371/journal.pone.0105056.

10. Arnold SV, Lipska KJ, Li Y et al. The reliability and prognosis of in-hospital diagnosis of metabolic syndrome in the setting of acute myocardial infarction. J Am Coll Cardiol, 2013; 62: 704-708. doi: 10.1016/j.jacc.2013.02.062.

11. McNeill AM, Rosamond WD, Girman CJ et al. The metabolic syndrome and 11-year risk of incident cardiovascular disease in the atherosclerosis risk in communities study. Diabetes Care, 2005; 28: 385-390.

12. Isomaa B, Almgren P, Tuomi T et al. Cardiovascular morbidity and mortality associated with the metabolic syndrome. Diabetes Care, 2001; 24: 683-689.

13. Sattar N, Gaw A, Scherbakova O et al. Metabolic syndrome with and without C-reactive protein as a predictor of coronary heart disease and diabetes in the West of Scotland Coronary Prevention Study. Circulation, 2003; 108: 414-419.

14. Hunt KJ, Resendez RG, Williams K, Haffner SM, Stern MP; San Antonio Heart Study. National Cholesterol Education Program versus World Health Organization metabolic syndrome in relation to all-cause and cardiovascular mortality in the San Antonio Heart Study. Circulation, 2004; 110: 1251-1257.

15. Moss AJ, Brown MW, Cannom DS et al. Multicenter Automatic Defibrillator Implantation Trial-Cardiac Resynchronization Therapy (MADIT-CRT): Design and clinical protocol. Ann Noninvasive Electrocardiol, 2005; 10 (4 suppl.): 34-43.

16. Zareba W, Klein H, Cygankiewicz I et al. Effectiveness of Cardiac Resynchronization Therapy by QRS Morphology in the Multicenter Automatic Defibrillator Implantation Trial-Cardiac Resynchronization Therapy (MADIT-CRT). Circulation, 2011; 123: 1061-72. doi: 10.1161/CIRCULATIONAHA.110.960898.

17. Goldenberg I, Kutyifa V, Klein HU et al. Survival with cardiacresynchronization therapy in mild heart failure. $\mathrm{N}$ Engl J Med, 2014; 370: 1694-1701. doi: 10.1056/NEJMoa1401426.

18. Alberti KG, Zimmet P, Shaw J. Metabolic syndrome: A new world-wide definition. A Consensus Statement from the International Diabetes Federation. Diabet Med, 2006; 23: 469-480. 
19. Barsheshet A, Goldenberg I, Moss AJ et al. Response to preventive cardiac resynchronization therapy in patients with ischaemic and nonischaemic cardiomyopathy in MADIT-CRT. Eur Heart J, 2011; 32: 1622-1630. doi: 10.1093/eurheartj/ehq407.

20. Marsan NA, Bleeker GB, van Bommel RJ et al. Comparison of time course of response to cardiac resynchronization therapy in patients with ischemic versus nonischemic cardiomyopathy. Am J Cardiol, 2009; 103: 690-694. doi: 10.1016/j.amjcard.2008.11.008.

21. Wikstrom G, Blomström-Lundqvist C, Andren B et al. The effects of aetiology on outcome in patients treated with cardiac resynchronization therapy in the CARE-HF trial. Eur Heart J, 2009; 30: 782-788. doi: 10.1093/eurheartj/ehn577.

22. Kirk JA, Holewinski RJ, Kooij V et al. Cardiac resynchronization sensitizes the sarcomere to calcium by reactivating GSK-3beta. J Clin Invest, 2014; 124: 129-138.

23. Carley AN, Taegtmeyer H, Lewandowski ED. Matrix revisited: Mechanisms linking energy substrate metabolism to the function of the heart. Circ Res, 2014; 114: 717-729. doi: 10.1161/ CIRCRESAHA.114.301863.

24. Wensley I, Salaveria K, Bulmer AC, Donner DG, du Toit EF. Myocardial structure, function and ischaemic tolerance in a rodent model of obesity with insulin resistance. Exp Physiol, 2013; 98: 1552-1564. doi: 10.1113/expphysiol.2013.074948.

25. Chokshi A, Drosatos K, Cheema FH et al. Ventricular assist device implantation corrects myocardial lipotoxicity, reverses insulin resistance, and normalizes cardiac metabolism in patients with advanced heart failure. Circulation, 2012; 125: 2844-2853. doi: 10.1161/CIRCULATIONAHA.111.060889.
26. Lichter JG, Carruth E, Mitchell C et al. Remodeling of the sarcomeric cytoskeleton in cardiac ventricular myocytes during heart failure and after cardiac resynchronization therapy. J Mol Cell Cardiol, 2014; 72: 186-195. doi: 10.1016/j.yjmcc.2014. 03.012 .

27. Yang S, Chen L, Sun S et al. Glycoproteins identified from heart failure and treatment models. Proteomics, 2015; 15: 567-579. doi: 10.1002/pmic.201400151.

28. Nyman K, Granér M, Pentikäinen MO et al. Cardiac steatosis and left ventricular function in men with metabolic syndrome. J Cardiovasc Magn Reson, 2013; 15: 103. doi: 10.1186/1532429X-15-103.

29. Limberg JK, Harrell JW, Johansson RE et al. Microvascular function in younger adults with obesity and metabolic syndrome: Role of oxidative stress. Am J Physiol Heart Circ Physiol, 2013; 305: H1230-H1237. doi: 10.1152/ajpheart.00291.2013.

30. Li ZL, Woollard JR, Ebrahimi B et al. Transition from obesity to metabolic syndrome is associated with altered myocardial autophagy and apoptosis. Arterioscler Thromb Vasc Biol, 2012; 32: 1132-1141. doi: 10.1161/ATVBAHA.111.244061.

31. Canale MP, Manca di Villahermosa S, Martino G et al. Obesity-related metabolic syndrome: Mechanisms of sympathetic overactivity. Int J Endocrinol, 2013; 2013: 865965. doi: 10.1155/2013/865965.

32. Ren SY, Xu X. Role of autophagy in metabolic syndrome-associated heart disease. Biochim Biophys Acta, 2014. Biochim Biophys Acta, 2015; 1852: 225-231. doi: 10.1016/j.bbadis. 2014.04.029. 